\title{
PRECARIOUS WORK EXPERIENCES OF RACIALIZED IMMIGRANT WOMEN IN TORONTO: A COMMUNITY- BASED STUDY
}

\author{
Dr. Stephanie Premji \\ Assistant Professor, \\ School of Labour Studies and \\ Department of Health, Aging and \\ Society, \\ McMaster University, \\ Hamilton, Ontario, Canada \\ spremji@mcmaster.ca \\ Megan Spasevski \\ Research Coordinator, \\ Access Alliance Multicultural Health \\ and Community Services, \\ Toronto, Ontario, Canada \\ Sehr Athar \\ Research Coordinator, \\ Access Alliance Multicultural Health \\ and Community Services, \\ Toronto, Ontario, Canada
}

\author{
Dr. Yogendra Shakya \\ Assistant Professor, \\ Dalla Lana School of Public Health \\ and Access Alliance Multicultural \\ Health and Community Services, \\ University of Toronto, \\ Toronto, Ontario, Canada \\ yshakya@accessalliance.ca \\ Jessica Merolli \\ PhD Candidate, ABD, \\ Department of Political Science, \\ McMaster University, \\ Hamilton, Ontario, Canada \\ Immigrant Women and Precarious \\ Employment Core Research Group ${ }^{1}$ \\ Access Alliance Multicultural Health \\ and Community Services, \\ Toronto, Ontario, Canada
}

\begin{abstract}
Despite their high levels of education, racialized immigrant women in Canada are over-represented in low-paid, low-skill jobs characterized by high risk and precarity. Our project documents the experiences with precarious employment of racialized immigrant women in Toronto. We conducted 30 semistructured interviews with racialized immigrant women. Participants were recruited through posted flyers, partner agencies, peer researcher networks and snowball sampling. Interviews were transcribed and analyzed using NVivo software. The project followed a community-based participatory action research model.

Participants faced powerful structural barriers to decent employment and additionally faced barriers associated with household gender relations. Their labour market experiences negatively impacted their physical and mental health
\end{abstract}


as well as that of their families. These problems further constrained women's ability to secure decent employment. Our study makes important contributions in filling the gap on the gendered barriers racialized immigrant women face in the labour market and the gendered impacts of deskilling and precarity on women and their families. We propose labour market reforms and changes in immigration and social policies to enable racialized immigrant women to overcome barriers to decent work.

\section{INTRODUCTION}

Tmmigrant women in Canada represent a sizeable and rapidly growing group. According to Census 2006 data, there are about 3.2 million immigrant women in Canada, representing 20 percent of the female population. A little over half (55 percent) of them are from racialized backgrounds ${ }^{2}$ (Chui, 2011). Compared to any other group, immigrant womenthose from racialized backgrounds and recent immigration in particularcontinue to experience the worst labour market conditions and outcomes. They are over-represented in low-paid, low-skill jobs characterized by high risk and precarity (Premji et al. 2010; Premji and Lewchuk 2013, Law Commission of Canada 2012; Fuller and Vosko 2008). They also experience elevated rates of under/unemployment (Chui 2011). Interestingly, these gaps occur despite the fact that immigrant women-and men-are more likely to be universityeducated than their Canadian-born counterparts. According to the 2006 Census, 33 percent of immigrant women and 49 percent of recent immigrant ${ }^{3}$ women have an undergraduate degree, compared to 23 percent of their Canadian-born counterparts (Galarneau and Morissette 2008).

While some have proposed that labour market gaps result from limitations in immigrants' soft skills, others have argued that state immigration and integration policies, restrictive professional accreditation systems, and discriminatory employer practices, all of which operate along racialized and gendered lines, serve to channel highly educated immigrants into under/unemployment (Teelucksingh and Galabuzi 2007; Man 2004). For example, Creese and Wiebe (2009), drawing on interviews with highly educated men and women from subSaharan Africa, found that women faced particular difficulties finding a "survival job" because demands for Canadian experience, credentials and accents were uneven across gendered employment sectors. However the authors found that women's greater investment in additional education placed them in a somewhat better position relative to men. Other studies have similarly documented racialized immigrant women's multiple and often concurrent strategies in response to deskilling and precarity, both in the labour market $(\mathrm{Ng}$ 
2006; McCoy and Masuch 2007; Cardu 2007) and in the household (Creese et al. 2008).

The impact of deskilling and ensuing precarity on racialized immigrant women is less clear. The impact on workers has traditionally been examined in terms of economic returns, occupational mobility and job satisfaction, though some studies have highlighted the implications for the health and well-being of workers, their families and communities (Lewchuk 2003; United Way Toronto and McMaster University 2013). A handful of studies have focused on immigrant populations, but they have lacked a gender-based perspective. For example, one study on the impacts of under/unemployment among highly skilled immigrants to Canada found that participants and their family members experienced poor mental health because of lack of income, loss of skills and social status and family pressures. In addition, participants experienced poor physical health due to stressful and strenuous working conditions. The study, however, included mostly men (72 percent) and did not present analyses by gender (Dean and Wilson 2009).

While labour market barriers to decent employment are relatively well documented, studies thus far have failed to address the role of racialized immigrant women's social locations, particularly with regards to their household and caregiving responsibilities. In addition, there is limited evidence on the full range of impacts of current trends in the labour markets on racialized immigrant women. These limitations with research are compounded by the fact that the voices of immigrant women, specifically those from racialized backgrounds, have largely been missing in policy framing and public debates about labour market and economic issues in Canada. In order to address these gaps, we sought to examine the precarious work experiences of largely universityeducated racialized immigrant women in Toronto, Ontario, Canada. Precarious employment broadly refers to high levels of job insecurity and instability and reduced benefits and protections, such as in jobs that are temporary, on-call, casual, on contract, and shift work based (Cranford et al. 2003; deWolff 2000; Fuller and Vosko 2008).

\section{METHODS}

This study was led by Access Alliance Multicultural Health and Community Services, a non-for-profit organization that provides community-governed primary health care services to disadvantaged immigrants and refugees in Toronto. Since 2006, Access Alliance has been leading a multi-phase research agenda on labour market barriers faced by racialized communities. In 2010, it agreed to collaborate on a project titled "Poverty and Precarious Employment in Southern Ontario" (PEPSO), led by Dr. Wayne Lewchuk of McMaster University and United Way Toronto, and funded by a Community University Research Alliance (CURA) grant from the Social Sciences and Humanities Research 
Council. As part of this collaboration, Access Alliance led one of six case studies for the PEPSO project, on the precarious employment experiences of racialized immigrant women. The study built on Access Alliance's previous research on the labour market barriers faced by immigrant and racialized communities (Wilson et al. 2011; Access Alliance Multicultural Health and Community Services 2012). Ethics approval was obtained from McMaster University Research Ethics Board.

The project brought together an interdisciplinary team of academic partners from McMaster University's School of Labour Studies, community agency partners from the settlement and employment sector, and immigrant women. In line with community-based research principles, Access Alliance trained and engaged seven racialized immigrant women as peer researchers in the study. Peer researchers each received over 40 hours of training in research design, ethics, recruitment, data collection and analysis and were involved in all aspects of the research. The team met in three collaborative meetings to jointly develop the research questions and study design. In terms of research questions, we wanted to find out:

1. Why and how racialized immigrant women are getting pushed into precarious types of jobs?

2. What are the economic, health and social impacts of being stuck in precarious jobs for racialized immigrant women and their families?

3. How do racialized immigrant women view and respond to (manage, subvert and resist) conditions and impacts of employment precarity?

Overall, we were interested in documenting the gendered dimensions and gendered impacts of the rise of precarious forms of employment in Canada as perceived and experienced by racialized immigrant women. In doing so, we hoped to better understand how gender, race and migration/immigration intersect with each other to create varied opportunities and inequalities for this population.

As the study was focused on understanding the pathways and impacts of precarious employment, we targeted participants who were struggling to get stable employment. Since we were interested in women who were actively participating in the labour market, we recruited women within the core workingage population (25-54). People chronically dependent on social assistance with limited labour market participation were excluded from the study.

We recruited for interviews 30 racialized immigrant women representing a diverse cross section in terms of country of origin, length of stay in Canada, migration/immigration pathway, household composition, education level and occupation. An important inclusion criterion was that participants must have lived in Canada for at least two years to ensure all participants had sufficient time to actively participate in the labour market and discuss in detail the causes, 
experiences and impacts of being stuck in precarious employment. To understand the causes and impacts of precarious employment among immigrants from different migration periods, we tried to recruit equal number of participants from three categories based on length of stay in Canada: newcomers (two to five years), medium-term immigrants (six to ten years) and longer-term immigrants (ten-plus years). While indicators for immigrant length of stay categories vary, we find this three category framework more suited to capturing how labour market and settlement experiences are affected by time in Canada

Women could participate in English or in one of the five languages spoken by research team members: Arabic, Dari, Nepali, Sgaw-Karen and Somali. Immigrant communities represented in these five language groups face high levels of economic marginalization but their voices remain underrepresented within mainstream research. The option to participate in these languages helped to reduce barriers to participation from members of these communities and offered the choice of speaking in the comfort of their first language irrespective of their level of fluency in English. A third of the study participants chose to participate in English including immigrant women from other than these five language groups (e.g., from Bangladesh, Pakistan, Sierra Leone, Mexico, Uruguay, China and the Philippines). Participants were recruited through posted flyers (translated in relevant languages), partner agencies, presentations to immigrant women programs, peer researcher networks, and through snowball sampling.

We conducted in-depth, semi-structured interviews. Interviews were then transcribed, with those conducted in a language other than English translated as appropriate. Transcripts were coded and analyzed using NVIVO 8 software. Research team members read a representative number of transcripts in order to develop a master coding framework that would capture important themes. The team periodically reviewed new themes that emerged during coding, and backcoded to all transcripts any that were relevant to the study's goals. Coded thematic summaries were then jointly analyzed using a "collaborative data analysis" process developed by Access Alliance. In addition, the team conducted a literature review and policy scan to map current evidence and policy directions related to the labour market participation and outcomes for racialized immigrant women.

Our analysis was guided by post-colonial feminist scholarship that has examined how inequalities based on gender, race and migration/immigration intersect to produce compounding and varied negative labour market outcomes for racialized immigrant women. We drew on critical feminist concepts such as "gendered occupational streaming" to examine how policy rationales and social practices perpetuate and normalize the streaming of racialized immigrant women into low-paid, front-line and highly precarious jobs (Dobrowski 2012). We similarly drew upon $\mathrm{Ng}^{\prime}$ s (2002) characterization of racialized immigrant women as a "captive labour force" whereby they are "essential" for the effective 
functioning of the labour market yet are treated as "disposable." In turn, the precarious nature of their jobs makes them "captive" and unable to find decent employment. Post-colonial feminist scholars have also highlighted how the root causes of inequalities lay with regressive migration/immigration policies and trends - both at national and global levels.

\section{RESULTS}

The demographic profile of participants is presented in Table 1.

Table 1

Demographic Profile of Study Participants

\begin{tabular}{|c|c|}
\hline Variable & $\begin{array}{c}\% \\
(\mathrm{~N}=30)\end{array}$ \\
\hline \multicolumn{2}{|l|}{ AGE } \\
\hline $30-39$ years & 33 \\
\hline $40-49$ years & 47 \\
\hline $50-59$ & 20 \\
\hline$\%$ Married or in a relationship & 80 \\
\hline$\%$ with university degree & 71 \\
\hline \multicolumn{2}{|l|}{ REGION/COUNTRY OF ORIGIN } \\
\hline West Central Asia/Middle East (Afghanistan, Iran) & 13 \\
\hline China and South East Asia (Burma, Philippines) & 24 \\
\hline South Asia (Bangladesh, Nepal, Pakistan) & 37 \\
\hline Africa (Somalia, Sudan, Sierra Leone) & 10 \\
\hline Central and South America & 6 \\
\hline \multicolumn{2}{|l|}{ LENGTH OF STAY IN CANADA (2011 as reference) } \\
\hline $2-5$ years & 37 \\
\hline $6-10$ years & 30 \\
\hline $11+$ years & 33 \\
\hline \multicolumn{2}{|l|}{ IMMIGRATION STATUS UPON ARRIVAL } \\
\hline Skilled Worker/Economic Class (Dependent) & 26 \\
\hline Skilled Worker/Economic Class (Primary Applicant) & 17 \\
\hline Government Assisted Refugees & 17 \\
\hline Refugee claimant & 13 \\
\hline Family sponsored & 13 \\
\hline Live-in caregiver & 7 \\
\hline Other & 7 \\
\hline
\end{tabular}

Participants were at least 30 years old and eighty percent of the participants were between 30 to 50 years of age. Almost three fourth of the participants (71 percent) had a university degree. In terms of length of stay in Canada, participants were evenly distributed in terms of newcomers, medium term immigrants, and longer term immigrants. Thirty percent of participants came through one of the refugee streams (Government Assisted Refugees or refugee 
claimant). Five (17 percent) of the participants were primary applicants in the Federal Skilled Worker program. The experiences of participants with precarious employment are discussed below.

\section{NATURE OF GENDERED PRECARIOUS EMPLOYMENT}

Participants were often pushed into long term trajectories of gendered low paid precarious employment that did not reflect their education and experience. They often worked in very low positions that were marginally related to their field. For example, participants from teaching and healthcare professions were working as personal support workers or daycare assistants. A chartered accountant from Albania shared why she accepted an accounting clerk position that was low paying, well below her skill level and often involved working overtime:

It was good for me because it was Canadian experience that I started there in the office. But what he did was that he didn't give me the raise that should be in the office. He gave me just $\$ 14$ an hour. That was very low. I actually accepted because it was as I said hard to find job like that. I thought anyway I'm getting some experience and I worked very hard there. I worked 12 and 13 hours a day ("Arlinda").

Others faced even worse job-skill mismatch. A doctor from Iran was juggling a cleaning job with a minimum wage job in a fast food chain. A psychologist from Sudan and a forestry expert from Nepal were working on commission as insurance brokers. Due to difficulties finding employment in their fields, a few participants from the business sector decided to shift to the non-profit sector. Participants from non-profit/community sector occupations obtained jobs in community or settlement agencies in Canada. However, everyone from this occupational background was working in very front-line low paying positions and mostly in the form of part-time, insecure contracts. Participants' husbands were also in precarious jobs that did not reflect their education and experience (e.g., chief engineer working as an elevator repair person, teacher working as a construction worker).

Participants' employment pathways showed very high levels of employment precarity marked by multiple short periods of employment and lengthy periods of unemployment between jobs. Often, they experienced this precarity over extended periods. For example, "Shristi", a forestry expert from Nepal, first worked at a Canadian Tire after coming to Canada. She worked there for 6 months, and also did housekeeping at a hotel during summers. She then did some occasional work as an interpreter. She applied for and obtained an internship through the Ministry of Natural Resources, and worked at that job for two and a half years. At the time of the interview, she was working on 
commission for an insurance company. Accordingly, participants' jobs provided them with little security and stability. For example, "Afsoon", a former teacher in Afghanistan, worked for 10 months as an on-call caregiver at child care centres. She would get called for work two to three times a week, always to different locations across the city. Other participants experienced insecurity/instability because their work was commission-based, for a temporary agency or on a shortterm contract. Yet others worked full-time for legitimate employers (e.g., convenience store owner) but were paid less than minimum wage, and experienced income insecurity as a result. Additionally, participants' jobs typically provided them with no benefits and protections:

With my current job, precarious is an understatement... Doesn't have any benefit...also and, doesn't have sick days. So when I miss a day of work, I don't get paid. And because of the days that we work, we don't even have holidays because Mondays are off for us. So most of the holidays, long weekends are Mondays. So we don't get paid for that Monday because it's not a working day. That was strategic....It's customer service, which is of course not what my dream job is ("Zaria").

In order to supplement their income, many had or were engaged in informal income generating activities. Their informal work was highly gendered in areas such as babysitting, cleaning, and cooking, and often paid far below minimum wage (e.g., \$5/hour). Longer-term immigrants, despite their very good to excellent English proficiency and the fact that half had upgraded their education, also experienced job-skill mismatch and precarious employment. For example, a participant from Bangladesh who immigrated in 2000 returned to school to complete a social work degree. In spite of her degree and lengthy experience working in a senior management position in an international development agency, she was working part-time (nine hours/week) as a family support worker. Participants with limited English proficiency and education found their options even more limited. Within a few months of arrival, most got streamed into low-paying factory jobs with few opportunities for professional development into better quality jobs.

\section{LABOUR MARKET STRATEGIES}

Participants used a wide range of employment services and job search strategies in their attempts to find decent employment. They attended resume clinics, consulted job search agencies, sent resumes, applied to jobs in-person, went through temporary agencies and networked. As one participant described, "every day I'm running, running, running to drop my resume" ("Len"). The process was often disempowering as participants often had to conceal their skills and experiences so that they could get any job: 
I just walked inside and said I'm asking if they have a job, something for me... I spoke to the owner and I asked him whatever you have please, I can accept any kind of job just to be near my apartment, my living place. And he said what is your profession? I said don't ask because I don't think that you can hire me for that, I never found for ten months. ("Arlinda")

In addition to job searching, participants sought to upgrade their education and gain experience. About 40 percent of participants reported participating in some kind of skills training (e.g., catering, food handling) and/or going back to school to get a new degree/diploma (e.g., Social Work, Early Childhood Education, AutoCAD). Some participants in regulated professions like health care went back to school to attempt to get their re-certification, though many did not want to start "from the bottom":

I don't want to upgrade economics because I have to start it from the bottom level right... I think this Early Childhood Education; this child-sitters job is not bad ("Yamu").

Participants with a higher level of education and those who were married were more likely to go back to school. In addition, many participants reported doing hundreds of volunteer hours for lengthy durations as part of their labour market strategy. This was particularly true for women from the healthcare, teaching, community/non-profit professions and for those who were experiencing long and scattered periods of unemployment. One internationally trained physician mentioned that she had been volunteering for over two years at a hospital, doing what she called "disrespectful work" as a patient escort. Several participants from teaching occupations indicated that they often worked for no pay in daycare centres in between on-call paid work.

\section{BARRIERS TO DECENT EMPLOYMENT}

In spite of these wide-ranging labour market strategies, participants faced a number of powerful structural barriers to decent employment. The key labour market barriers were:

- Non-recognition of foreign credentials (and "Canadian experience" requirement)

- Racialized discrimination (including based on religious affiliation and accent)

- Language barriers

- Information and access barriers about services

- Limited professional network 
Participants at times experienced these barriers in gendered and racialized ways:

... I remember when I was asking someone from the bank how did you apply, because I knew that she was also an immigrant, and she was saying that oh you're better in the care giving profession because you're Filipino. I was like, okay. So it's like putting a label on me that you cannot work for this kind of field. When in fact I was telling her that I have experience working for a bank ("Gemma").

Women additionally faced a range of social barriers to decent employment, namely those associated with household gender relations. The key social barriers included:

- Social isolation and limited social support system

- High load of household and caregiving work

- Lack of supportive male partners

- Lack of affordable childcare

A large number of participants spoke about the intense loneliness they felt in Canada. Without the social support system they used to have in their country of origin, most of the household and caregiving responsibilities fell solely on them. Most participants mentioned that their husband rarely shared in household work:

...People say yeah obviously go [for the job]. But that meant for me to work harder because I have to work outside and inside the house, nobody did anything in the house...Exactly. It never occurred in his [husband's] mind that he could cook or clean or do something. Nothing, like he could help me out (“Lucia”).

Accordingly, participants saw their career paths limited due to childcare and family responsibilities:

My husband was telling me to do economics sector too but when I saw the course offered, I felt hard. Even though I did masters from there. And I had to handle in my house, two children, and I can't spend money from there to here it was so like low. So I had to survive for the present, I didn't have, I could not think for the future at that time. I really have to survive, because only we came with our like clothes and suitcase right. So I have to, because I have the small children and so I had to think many things so, I better quit about economics ("Yamu"). 
These barriers were compounded by the absence of affordable child care:

Well actually yeah, you could say child care [was a barrier] because I didn't even find a decent baby sitter and it was quite expensive and any help that I could get at home for kids it was quite expensive. So it was cheaper for me to stay home instead of going out to work. That prevent me for getting a better work. I guess because, it was a hard choice. My kids or work. I wanted to grow professionally and do a life for myself, I wanted to but I guess the lack of getting good baby sitting and reasonable cost, that could be ("Lucia").

In addition to structural and social barriers, women experienced barriers related to their migration/immigration experiences. For example, two participants came through the live-in caregiver program, a federal program geared at bringing women from other regions of the world-particularly the Philippines - to serve as low-cost "flexible" care workers in Canada. The participants talked about the many difficulties they encountered in meeting the mandatory work hour requirement to quality for permanent residency and in attempting to transition to stable professions. One of the participants wanted to go into nursing and the other into banking. Neither of them had been able to pursue these career aspirations. Other participants were caught in human trafficking and problematic spousal sponsorship arrangements that reinforced their dependent status and limited their social economic participation.

\section{IMPACTS OF PRECARIOUS EMPLOYMENT}

\section{HEALTH IMPACT}

Many participants claimed that their health and the health of their family deteriorated after coming to Canada. For example, "Anika", an OBGYN in Bangladesh who faced unemployment in Canada, explained:

Because when I came first, after one and a half years when I started to realize the environment, the future, I became stressed. For that reason I think I got, suddenly I had some neck pain or something. I went to the doctor and he said my blood pressure was way high at the time. So he did all the investigations and since this I'm taking my medication for blood pressure.

More than half of the participants experienced acute mental stress and depression, and some admitted to taking anti-depressants. A third of participants had trouble sleeping because of the excessive stress. Many mentioned that their self-esteem and sense of self had been affected. In addition, almost all participants reported experiencing multiple physical health problems including digestive problems (e.g., ulcers), cardio-vascular illnesses, chronic muscular- 
skeletal pain and diabetes. Participants articulated that job and economic hardships were the source of the health issues they were facing:

And well I have problems that I began to find work stress, problems at work, problems in the house already with family problems. I got sick, I really got sick, I had a panic attack at the [job] and I guess it's due to the stress that I was going through. And then the doctor suggest to me that it was too much for me, all this work and the hours and the shift and nights and that stress because of my family, the problems. I could not get the hours that I wanted to. At work I find myself with lots of work, lots of issues, lots of issues that I have to deal with. I deal successfully but expenses of my health ("Lucia").

So I went back home and I stayed for a year because I was too frustrated I was trying all means, it was not working my self-esteem kept going down, that I was from a place where people used to highly esteem me and now I'm in a place where nobody cares about me, I don't even make a difference anywhere ("Zaria").

Participants also spoke about the negative impact of precarious work on their children and husbands' health:

Sometimes I really feel upset but I cannot share with anyone. If I share with my elder one is 16, I can share so many things, she is like my friend now and she is really one of my good friends too. But when I share with her she will also get upset, why her mom will do so many household work and try for jobs and run here there. That's why I keep quiet myself and sometimes I feel very tired, lonely and upset too ("Rupa").

He [husband] felt like he lost his health, mental health and physical health also. He has chronic pain and he went to a year it is a health benefit is only 15 weeks so altogether he thought as a man, because his role is supposed to be supportive role, active role in the family but he became vulnerable and independent. So he was not feeling good ("Sadia").

Participants did not resort to negative coping strategies (smoking, alcohol, etc.). Instead, several women talked about drawing on their knowledge of nutritious food and health promoting activities - including spending time with family and children - to keep their family healthy in spite of the challenges they were facing:

And even I try especially when he [husband] comes [inaudible] and then we go for a walk, at least walking half an hour, one hour together, and at that time we talk about jobs and some other things that also makes mental, like cools down the mental stresses sometimes. So it's talking and walking, physical exercise, those things. But other than that he doesn't go to gym or he's not taking any advice from the doctors... Yeah he doesn't want [to do physical exercise after 
truck driving shifts]. But walking it's okay, but still sometimes he doesn't want...You have to trick him ("Shristi").

The health promoting role took on by participants was also a source of stress. With a limited social support system in Canada, this function fell heavily on individual immigrant women while it would have been shared in their country of origin. These health problems and coping strategies in turn further constrained women's ability to secure decent employment.

\section{SOCIAL IMPACT}

Many participants described significant increases in overall responsibilities, and an intensification of pressure and stress that worsened their post-migration household gender relations and social status:

I was doing everything. I was cleaning, I was cooking everything. Because as I said my husband he went to work at 5:00 in the morning until 5:00 or 6:00 in the evening. And as soon as I got home I starting to do the things for cooking, cleaning doing everything. [Interviewer asks: 'And you were working 12 hours too?' And participant replies:] “Yes, from 8:00 a.m. until sometimes 7:00 or 8:00 in the evening. As soon as I got home, thank God my apartment was close to work, I didn't lose time to come and go, but I did until 1:00 a.m. I was taking care of the other things. Like a robot ("Arlinda").

I deprived myself to be the woman that I could be in the workforce, just to keep the family together, ironically. I choose that to keep everybody happily together. And at the end, it didn't work, so. It affects me emotionally a lot, a lot. ("Lucia")

As well, social pressures resulting from precarious employment conditions had many negative repercussions on household/family relationships and wellbeing including (1) high levels of household relationship strain and tensions; (2) delays and disruptions in household communication (among spouses, between parents and children); (3) reduction in family time and leisure time; (4) weakening of household strategies for problem solving and promoting positive family health; and (5) overall sense of disempowerment at the family/household level. Participants were particularly troubled by their inability to spend quality family time:

As a family we don't get to do anything because all of the time, I work the days that people are actually out there to do it. I live by Chucky Cheese and we hardly get time to even go into Chucky Cheese and play. So it's kind of hard because then this little time I have, I want to make sure that there is food in the house. I want to make sure there is laundry done. I want to make sure the house is organized, then by the time I'm done, I'm tired ("Zaria"). 
No he's [son] better now but my only problem with him is, especially when I went back to school is he's constantly asking for attention... one time I was yelling at him last weekend and I asked him, I'm so tired and I'm also sick and I told him 'what do you want from me? Tell me, I know you can speak now, tell me what do you want to say to mommy?' And he was saying that 'I just want you to hug me.' Because he was saying that it seems that, since I was always busy I don't really look as often as we did before, I don't play with him anymore, and he said; 'you don't hug me as much as you did before.' So at 3 years old 'oh my goodness', it's like 'wow'... I feel so guilty ("Gemma").

While some families developed a strong family bond and supportive strategies that helped buffer the negative impacts of precarious employment, in other cases economic and social stress led to family break down and separation:

And the family relation is related with the issue, very much related. Because you will see lots of family conflict, children are dropping from home, breaking down the family, family ties become loose or respect issue when man cannot play the role as a healthy husband. Even with the family personal relation and the family relation. Emotional relation it change through the employment and economic situation also ("Sadia").

The many stressors, strains and disruptions in everyday household functioning had adverse consequences for racialized immigrant women's capacity to negotiate a healthier work-life balance and an equitable division of labour in the household. These gendered social outcomes from precarious employment in turn produced negative employment and health pathways for the women, and undermined their sense of identity and social position within Canadian society.

\section{DISCUSSION}

Our study makes important contributions in filling the gap in Canadian evidence on the gendered barriers racialized immigrant women face in the labour market and the gendered impacts of deskilling and precarity on women and their families. Results provide rich insights about how racialized immigrant women face triple intersecting layers of barriers and inequalities-based on gender, race and migration/immigration - as they attempt to find a good job, negotiate work-life balance, and take care of their family within the postmigration context in Canada.

Analysts from Statistics Canada (Picot et al. 2007; Picot and Sweetman 2005; Galarneau and Morissette 2004), the Toronto Immigrant Employment Data Initiative (Preston and D'Addario 2008; Preston et al. 2011) and the Ontario Office of the Fairness Commissioner (see, for example, their 2013 report titled $A$ Fair Way to Go) have produced a wealth of evidence about the labour market 
barriers experienced by immigrants in Canada. This body of evidence has shown that the top cited barrier is the non-recognition of foreign credentials and experiences by professional licensing bodies and employers. Other barriers include information gaps, linguistic barriers, limited professional networks, the requirement for "Canadian experience", and direct forms of discrimination. Our study shows that these same barriers prevent racialized immigrant women from getting stable employment that match their skills and aspirations. But like for all women, barriers to stable employment extend beyond labour market factors, though these are rarely addressed in studies of precarious paid labour. Our study adds to the existing literature by demonstrating that social barriers absence of a social support system, high burden of household work, lack of affordable childcare-directly prevents many racialized immigrant women from pursuing employment that matches their skills and goals, or creates delays in their job search processes.

Crucially, our study captures the gendered ways in which racialized immigrant women are impacted by these barriers. While internationally educated male immigrants are ending up driving taxis and working in factories, internationally educated female immigrants (doctors, psychologist, teachers, engineers, forestry experts, chartered accountants, etc.) are ending up in low paying gendered occupations such as hotel room attendants, personal support workers, daycare assistants, servers at fast food chains, front-line community workers, and office clerks. Often, these jobs are part-time, contract-based or oncall. This trend reflects what post-colonial feminists refer to as the "racializedgendered division of labour" in which low-wage, socially undervalued or "unproductive" work, and precarious types of jobs are systematically offloaded to women, particularly immigrant women and women from racialized backgrounds. In turn, the feminization and racialization of such occupations trigger a further decline in the wage rate, job security and social value of these occupations.

Our findings indicate that racialized immigrant women often experience lengthy periods of unemployment in between unstable jobs. Working informal jobs (often in gendered areas like babysitting, cleaning, and catering), working formal jobs without pay (e.g., putting in extra hours as daycare assistants without pay), or doing extensive volunteer work were common responses for many women facing employment precarity. This phenomenon appears to be so widespread that it is fuelling a large underground "shadow economy" of cheap labour in the childcare, cleaning and catering sectors. A recent survey with 453 immigrant families in Toronto found that almost half of the participants (46 percent) were taking part in informal income generating work, with higher rates for immigrant women (57 percent) (Aktar et al. 2013). The lines between paid formal work, unpaid formal work, informal work, volunteer work and household work intersect in blurred and contentious ways for racialized immigrant women. Feminist scholars have documented the "double workday" 
that many working women have to endure. The excessive workload that our participants described appears to be much more than a double workday.

Our study also lends support to the "healthy immigrant effect", which posits that immigrants' health is generally better than that of their Canadian-born counterparts, but deteriorates after arrival (McDonald and Kennedy 2004; Newbold 2006). Specifically, it brings to the forefront the contributory role of employment conditions to this process by showing that being stuck in precarious employment leads to damaging mental and physical health impacts on racialized immigrant women and their families. Employment and income are now recognized as core determinants of health that impact other determinants including food security, education, access to services and social inclusion (Public Health Agency of Canada 2004; Lewchuk et al. 2008 Raphael, 2004; Lynch et al. 2000; Lightman et al. 2008; Marmot and Wilkinson 2006). Researchers from the Employment Conditions Knowledge Network (EMCONET) established under the auspices of the World Health Organization have compiled very convincing bodies of evidence showing how workers in precarious employment and vulnerable working conditions are at increased risk for cardio-vascular, musculoskeletal, respiratory, mental health, and chronic illnesses like diabetes and cancer (Benach et al. 2010). Our study builds on this evidence, and provides new evidence on the range of social strains of precarious employment on women and their families. It highlights the cyclical relationship between precarious employment and physical, mental and social well-being and shows that these dynamics contribute to pushing racialized immigrant women into long term precarious employment trajectories.

\section{CONCLUSION AND RECOMMENDATIONS}

In focusing on barriers and challenges faced by racialized immigrant women - one of the most marginalized groups in Canada - this study has documented deeply rooted structures of inequalities based on gender, race and migration/immigration. Irrespective of education level and professional work experience, immigrant women from racialized backgrounds are getting pushed into gendered occupations marked by low wages and high levels of precarity. Nor is precarious employment limited only to newcomers. Narratives from nonrecent immigrant participants help to capture how and why immigrant women are still stuck in low paying precarious jobs even after living in Canada for over 10 years. However, current policy decisions and public discussions continue to ignore this vulnerable group and operate on the expectation that racialized immigrant women should absorb the social costs and externalities associated with precarious jobs and poverty. This trend needs to be urgently reversed.

Based on our findings, we argue that promoting stable employment and wellbeing of racialized immigrant women needs to become one of the top policy 
priorities in Canada and a key benchmark indicator for measuring and achieving a more equitable nation.

To overcome these deep inequalities will require equally deep and bold policy changes and social transformation-including a transformative rethink of the way we conceptualize and value work (including paid, volunteer, informal work, and household work). Further, we need to make our immigration, labour market, settlement and social policies more gender-sensitive, discrimination free, and empowering such that even immigrant women with limited education can find equitable opportunities and supports to achieve stable employment and live a prosperous healthy life.

In terms of labour market reforms, we echo policy recommendations advocated by the Workers' Action Centre, the Colour of Poverty Campaign, the Law Commission of Ontario and the Ontario Office of the Fairness Commissioner:

1. Re-introduce the employment equity legislation in Ontario (and in other provinces).

2. Introduce comprehensive workplace anti-discrimination legislation that ensures that all workplaces have accessible and proactive antidiscrimination policies (in terms of hiring, promotions, pay and treatment of employees). Anti-discrimination legislation needs to be applied to accreditation and recertification bodies as well to institute a faster, fair and accessible foreign credential recognition process.

3. Ensure more effective enforcement of Employment Standards regulations and Occupational Health and Safety regulations to promote safe exploitation-free work environments and extend protections specifically to those in non-standard, non-unionized precarious work environment.

4. Increase the minimum wage rate periodically to above poverty rate and adjusted to inflation. Introduce a Fair Wage and Benefits Policy to prevent a 'race to the bottom' in terms of employee wage and benefits.

Based on findings from this study, we emphasize the need for a strong gendersensitive lens in all of the above policy solutions. For example, we need to ensure that those occupations that have a high proportion of vulnerable women (childcare worker, room attendant, personal support worker) are properly regulated and supported to prevent exploitative working conditions, and to ensure fair wages and benefits. In addition to the healthcare sector, we need to ensure that other female dominated sectors like teaching also adopt a faster and fairer foreign credential recognition process. These labour market reforms need to be complemented with changes in immigration and social policies: 
1. Introduce a national level universal affordable childcare program.

2. Remove highly restrictive conditions and heavy work hour requirements for live-in caregivers that expose them to exploitation and undermine their access to more stable career paths.

3. Make employment insurance and social assistance programs more gender-sensitive and newcomer friendly such that these programs serve as equitable social safety nets for immigrant women negatively impacted by labour market and economic trends.

4. Implement gender-sensitive training to employment and settlement counsellors to enable them to proactive tackle structural barriers and discrimination that racialized immigrant women workers face in the labour market.

Many of these policy solutions are about training and better enforcement and can be implemented immediately by reorienting existing service delivery infrastructure and government funding formulas. Others like universal childcare program and provincial employment equity require mobilizing cross-sectoral collaboration and broader public/government consensus, supported by new earmarked funding.

The first step for tackling these difficult tasks is to engage racialized immigrant women in a leadership capacity in research, program planning, policy making, and public education programs. For example, promoting gender equity within immigrant households can only be achieved if we involve immigrant women themselves in developing policy solutions and culturally/contextually sensitive gender education programs. Failure to involve immigrant women meaningfully will not only undermine our ability to find real solutions but also make researchers and policymakers complicit in the social apparatus that is reinforcing inequalities. Our community-based experience shows that with appropriate training and opportunity, marginalized immigrant women can indeed do high quality research to generate tangible evidence and informed policy solutions.

\section{NOTES}

1 Wisal Abugala, Lindsay Angelow, Khin Myo Lwin, Hareda Mohamud, Moo Lay Naw, Almaz Reda, Muriam Salman, Parveen Shojai, Mira Shrestra, Thuy Tran, Hamida Zia, Charlotte Yates. This paper was made possible by the support of funds from the United Way Toronto- McMaster University SSHRC CURA project on Poverty and Employment Precarity in Southern Ontario.

2 Statistics Canada and other mainstream agencies use terms like "visible minorities" or "ethno-racial groups" to refer to people from non-White/non-European backgrounds. These terms relate primarily to number and colour. They assume dominant groups are free from race/ethnicity. Such terms also lead to 
'minoritization' even in contexts where racialized groups are a majority. In line with the Canadian Race Relations Foundation, we use the term "racialized groups." This term recognizes the dynamic and complex process by which racial categories are socially produced by dominant groups in ways that entrench social inequalities (Galabuzi, 2001).

3 Statistics Canada defines "recent immigrants" as those who arrived in Canada within the last 10 years.

\section{REFERENCES}

Access Alliance Multicultural Health and Community Services. 2012. Where are the Good Jobs? Toronto: Access Alliance. Retrieved July 162014 http://accessalliance.ca/research/where_are_the_good_jobs

Akter, N., S. Topkara-Sarsu, and D. Diane. 2013. Shadow Economies: Economic Survival Strategies of Toronto Immigrant Communities. Toronto East Local Immigration Partnership workgroup (Action for Neighbourhood ChangeTaylor Massey, Bangladeshi-Canadian Community Services, Chinese Canadian National Council-Toronto Chapter, Neighbourhood Link, Riverdale East African Association, WoodGreen Community Services), Toronto: Wellesley Institute. Retrieved July 162014 http://www.wellesleyinstitute.com/wp-content/uploads/2013/10/ShadowEconomies-FINAL.pdf

Benach, J. Muntaner, C. and V. Santana. 2010. Employment Conditions and Health Inequalities. Final Report to the WHO Commission on Social Determinants of Health (CSDH). Retrieved July 162014

http://www.who.int/social_determinants/resources/articles/emconet_who_report. pdf

Cardu, H. 2007. "Career nomadism and the building of a professional identity in female immigrants". Journal of International Migration and Integration/Revue de l'integration et de la migration internationale. 8(4): 429-439.

Chui, T. 2011. "Immigrant Women". Statistics Canada Catalogue no. 89-503-X. Retrieved July 162014 http://www.statcan.gc.ca/pub/89-503-x/2010001/article/11528-eng.pdf

Cranford, C., Vosko, L. and Zukewich, N. 2003. Precarious Employment in the Canadian Labour Market: A Statistical Portrait. Retrieved July 162014 http://www.yorku.ca/julabour/volume3/cranfordetal_justlabour.PDF

Creese, G., Dyck, I, McLaren, A.T. 2008. The 'flexible'immigrant? Human capital discourse, the family household and labour market strategies. Journal of International Migration and Integration/Revue de l'integration et de la migration internationale. 9(3): 269-288.

Creese, G., and Wiebe, B. 2009. "'Survival employment': Gender and deskilling among African immigrants in Canada." International Migration. 50: 56-76. 
Dean, J. A., and Wilson, K. 2009. "Education? It is irrelevant to my job now. It makes me very depressed ...: exploring the health impacts of under/unemployment among highly skilled recent immigrants in Canada". Ethnicity and Health. 14(2): 185-204.

de Wolff, A. 2000. Breaking the myth of flexible work: Contingent work in Toronto. A study conducted by the contingent workers project. Toronto, ON: Contingent Workers Project.

Dobrowolsky, A. 2012. Complicating and Contesting Narratives Around Diversity and Equality: Economic Immigration and Women. Edmonton: Canadian Political Science Association Annual Conference.

Fuller, S. and Vosko, L.F. 2008. “Temporary Employment and Social Inequality in Canada: Exploring Intersections of Gender, Race and Immigration Status". Social Indicators Research 88: 31-50.

Galarneau, D., and Morissette, R. 2004. "Immigrants: Settling for less?" Perspectives on Labour and Income. Vol. 5, no. 6. Statistics Canada Catalogue no. 75-001-XIE. Analytical Studies Branch Research Paper Series. Ottawa.

Galarneau, D., and Morissette, R. 2008. "Immigrants' Education and Required Job Skills." Perspectives on Labour and Income 9(12). Statistics Canada. Retrieved July 162014 http://www.statcan.gc.ca/pub/75-001-x/2008112/pdf/10766-eng.pdf.

Law Commission of Ontario 2012. Vulnerable Workers and Precarous Work. Toronto: Law Commission of Ontario.

Lewchuk, W., de Wolff, A., King, A., and Polanyi, M. 2003. "From job strain to employment strain: Health effects of precarious employment." Just Labour 3: 23-35.

Lewchuk, W., Clarke, M., de Wolff, A. 2008. "Working without commitments: Precarious employment and health." Work, employment and society. 22: 387406.

Lightman, E., A. Mitchell, and B. Wilson. 2008. Poverty is Making us Sick. Toronto: The Wellesley Institute.

Lynch, J. 2000. "Income inequality and health: Expanding the debate." Social Science and Medicine 51: 1001-1005.

Man, G. 2004. "Gender, work and migration: Deskilling Chinese immigrant women in Canada." Women's Studies International Forum. 27(2): 135-148.

Marmot, M., and Wilkinson, R. 2006. Social Determinants of Health. 2nd ed. London: Oxford University Press.

McCoy, L., and Masuch, C. 2007. "Beyond "Entry-level" Jobs: Immigrant Women and Non-regulated Professional Occupations." Journal of International Migration and Integration/Revue de l'integration et de la migration internationale. 8(2): 185-206. 
McDonald, JT, Kennedy, S. 2004. Insights into the 'Healthy Immigrant Effect': Health Status and Health Service Use of Immigrants to Canada. Social Science and Medicine 59(8):1613-27.

Newbold, KB. 2006. Chronic Conditions and the Healthy Immigrant Effect: Evidence from Canadian Immigrants. Journal of Ethnic and Migration Studies. 32(5):765-84.

Ng, R. 2002. "Training for Whom? For What? Reflection on the Lack of Training Opportunities for Immigrant Garment Workers." NALL Working Paper \# 66

$\mathrm{Ng}$, R. 2006. Learning to be good citizens: informal learning and the labour market experiences of professional Chinese immigrant women. Final Report for the Centre of Excellence on Research on Immigration and Settlement (CERIS). Toronto.

Office of the Fairness Commissioner (OFC). 2013. A Fair Way to Go: Access to Ontario's Regulated Professions and the Need to Embrace Newcomers in the Global Economy (OFC publication No. 978-1-4606-0560-8). Toronto, Ontario: Canada. Queen's Printer for Ontario.

Picot, G., Hou, F., and Coulombe, S. 2007. "Chronic Low Income and Lowincome Dynamics Among Recent Immigrants." Statistics Canada Catalogue no. 11F0019MIE - No. 294. Analytical Studies Branch Research Paper Series. Ottawa.

Picot, G., and Sweetman, A. 2005. "The Deteriorating Economic Welfare of Immigrants and Possible Causes: Update 2005." Statistics Canada Catalogue no. 11F0019MIE - No. 262. Analytical Studies Branch Research Paper Series. Ottawa.

Preston, V., and D'Addario, S. 2008. "Recent Immigrants in the Canadian Labour Market: Exploring the Impacts of Gender and Racialisation." Pp. 139-164 in Refugees, recent migrants and employment: challenging barriers and exploring pathways, edited by McKay, S. New York: Routledge.

Preston, V., Chua, J., Phan, M., Park, S., Kelly P., and Lemoine, M. 2011. “What are immigrant's experiences of discrimination in the workplace." TIEDI Analytical Report 21. Toronto: May 2011.

Premji, S., Duguay, P., Messing, K., and Lippel,K. 2010. "Are immigrants, ethnic and linguistic minorities over-represented in jobs with a high level of compensated risk? Results from a Montreal, Canada study using census and workers' compensation data." American Journal of Industrial Medicine 53: 875885.

Premji, S. and Lewchuk, W. 2014. "Racialized and gendered disparities in health and safety among Chinese and white workers in Toronto, Canada." Ethnicity and Health 19(5) 512-528.

Public Health Agency of Canada (PHAC). 2004. The social determinants of health: Employment security as a determinant of health. Retrieved July 162014 http://www.phac-aspc.gc.ca/ph-sp/oi-ar/04_employment-eng.php 
Raphael, D. Ed. 2004. Social Determinants of Health: Canadian Perspectives. Toronto, Ontario: Canadian Scholars Press Inc.

Teelucksingh, C. and Galabuzi, G-E. 2007. “Working precariously: the impact of race and immigrant status on employment opportunities and outcomes in Canada." Pp. 202-208 in Race and Racialization: Essential Readings, edited by Das Gupta, T., James, C.E., Roger, C.A.M., Galabuzi, G-E., Andersen, C. Toronto: Canadian Scholars' Press.

United Way Toronto and McMaster University. 2013. "It's More than Poverty. Employment precarity and household well-being." Retrieved July 162014 http:// pepsouwt.files.wordpress.com/2013/02/its-more-than-poverty-feb-2013.pdf Wilson, R., Landolt, P., Shakya, Y., Galabuzi, G., Zahoorunissa, Z. and Pham, D. 2011. Working Rough, Living Poor: Employment and Income Insecurities Faced by Racialized Groups in the Black Creek area and their Impacts on Health. Toronto: Access Alliance Multicultural Health and Community Services. 